Young teenagers' perceptions of their own and others' bodies: A qualitative study of obese, overweight and 'normal' weight young people in Scotland

Wills*, W., Backett-Milburn**, K., Gregory**, S. and Lawton**, J.

*Centre for Research in Primary and Community Care, University of Hertfordshire ** Research Unit in Health, Behaviour and Change, University of Edinburgh

\begin{abstract}
The rise in numbers of overweight/obese children in the UK is causing widespread concern. Biomedical constructions of body acceptability and 'good health' mean that overweight/obese young people are frequently seen as deviant. The socio-cultural contexts within which young teenagers become fat, and lay conceptualisations of fatness, have largely been ignored. This qualitative study involved in-depth interviews with teenagers aged 13-14 years $(\mathrm{n}=36)$, drawn from families living in areas classified as socioeconomically disadvantaged. Half of the sample had a BMI classifying them as overweight or obese, whilst the remainder were classified as being 'normal' weight. Participants' embodied perceptions of fatness were complex and sometimes contradictory. We discuss what young teenagers perceive the influences on fatness and body size to be; the professed consequences of being fat; participants' experiences of attempting to lose weight; and, their reported interactions with friends and family relating to fatness and dieting. Participants rarely mentioned any health-related consequences of their own and others’ fatness, although wearing 'nice' clothes and being slowed down were raised as considerations by
\end{abstract}


girls and boys respectively. 'Normal' weight teenagers who disliked their bodies or who wanted to lose weight often claimed to be anxious about this. Being very obese also led to anxiety and reported attempts at 'crash dieting'. Acceptance of body size/shape was, however, common amongst the overweight and obese teenagers, although some had attempted weight loss. The teenagers in this study were rarely supportive of friends or family who attempted to lose weight and frequently disagreed with others' perceptions of fatness. These findings are important as they contradict the common perception that being overweight/obese is related to body dissatisfaction and that young people have a fear of fatness.

Keywords: Young teenagers; obesity; overweight; body image; qualitative study 


\section{Young teenagers' perceptions of their own and others' bodies: A qualitative study of obese, overweight and 'normal' weight young people in Scotland}

\section{Introduction}

The rise in numbers of overweight and obese children in the UK has caused widespread concern about the medical, financial and social consequences of such an increase in levels of fatness (National Audit Office, 2001; Royal College of Physicians, 2004). Overweight and obese young bodies are viewed by many public health and health care practitioners as needing attention because of the continued focus on biomedical constructions of appropriate body size and its relationship to 'good health'. Acceptance of the view that 'thin is good' and 'fat is bad' (Evans, 2004) is considered paramount for successful public health control. Overweight or obese individuals are, therefore, seen as deviant and deserving of surveillance aimed at compliance with the so-called 'thin-ideal' body shape (Lupton, 1994; Featherstone, 1991; Williams \& Germov, 1999). Aside from the apparent medical and financial costs, such an approach is deemed justified because of perceived negative consequences for well-being of being overweight or obese.

It has been suggested that the early teenage years are important in terms of peer relationships and 'fitting in' (Miles, Cliff \& Burr, 1998). Whilst it has been argued that overweight teenagers have few friends (Strauss \& Pollack, 2003), there is a lack of evidence that this is detrimental to teenagers' sense of well-being. Overweight youth are often argued to be at greater risk of bullying and teasing than their thinner peers (Janssen, Craig, Boyce \& Pickett, 2004), yet there is evidence that body size is not predictive of weight-based teasing (Eisenberg, Neumark-Sztainer \& Story, 2003). Strauss (2000) found evidence that, particularly for white girls (not boys) aged 13-14 years, obesity is related to 
lowered self-esteem. Strauss remarks that this is not surprising given the pressure on white girls to engage with cultural norms of thinness.

The perspectives of 'normal' weight, overweight and obese individuals, children and young people in particular, are missing from current public health debates about obesity. Most studies concerned with examining obesity amongst children and young people, both in the UK and elsewhere, have failed to take account of the micro-environments in which young people live. Little is known, for example, about whether socio-cultural differences exist in lay conceptualisations of fatness, irrespective of levels of overweight and obesity in specific social groups. Some of these studies have suggested that there is no longer a relationship between levels of childhood obesity in the UK and social class (Jeffery, Voss, Metcalf, Alba \& Wilkin, 2004; West \& Sweeting, 2004) although children in the most deprived families in Scotland have been shown to have a higher risk of becoming obese than their peers in more affluent families (Armstrong \& Reilly, 2003). Scottish schoolchildren are also becoming overweight at a faster rate than children in England (Armstrong \& Reilly, 2003).

The rise in prevalence of overweight and obesity is set, paradoxically, within a cultural context of dieting, other weight loss behaviours and eating disorders (O’Dea, 2004). Dieting amongst girls, in particular, has been associated with extreme restricted eating and weight-related anxiety (Nowak, 1998). Depressive symptoms have also been found to be more prevalent amongst girls with low body esteem and those trying to lose weight. Whilst eating disorders are diagnosed in only a minority of young people, it is perhaps misguided to believe that disordered eating is only evident in a 'few sick girls' (Frost, 2001). It has been suggested that a normalised view of eating behaviour and body image has been lost 
(O’Dea, 2004) whilst the numbers of young people becoming overweight and obese continues to rise. Being fat is considered abhorrent by many non-fat young people and adults alike (Frost, 2001; Wardle, Volz \& Golding, 1995) and a fear of becoming overweight is common amongst non-clinical populations of non-overweight children and young people as well as amongst those diagnosed with eating disorders (Sweeting \& West, 2002).

Most research on dieting and body image has focused on young women and girls because, traditionally, it is girls who are expected to engage with issues of body conformity (Bordo, 1993). There is, however, evidence that boys and young men also place great importance on their appearance and that they, too, ‘do looks’ (Frost, 2003), albeit perhaps for different reasons to girls (Frosh, Phoenix \& Patman, 2002). Whilst Frost (2003) has argued that girls have always been defined by their bodies, boys have only more recently engaged with popularist activities associated with body image and appearance, such as shopping for clothes and 'working out'. Hence, it is no longer possible to engage in debates about young bodies without considering how boys' bodies are defined and experienced by boys themselves.

In this paper we report findings from a qualitative study of 13 and 14 year olds from socioeconomically disadvantaged families living in Eastern Scotland. Drawing on these data, we explore the embodied perceptions of obese, overweight and 'normal' weight young teenagers, within the socio-cultural contexts in which these young teenagers live their everyday lives. By drawing on the perspectives of young teenagers, we aimed to discover whether, and how, weight and body size infiltrate other areas of teenagers' everyday lives; 
how these issues are experienced and perceived; and whether medical definitions of fatness are reflected in young peoples' discursive concerns.

\section{Methodology and study design}

A qualitative approach allowed us to explore themes which emerged during data collection, rather than simply assessing those formulated at the study’s outset (Britten, Jones, Murphy \& Stacy, 1995). This approach also allowed analysis and interpretation of the data to be developed during the course of the study, and to be guided iteratively by the experiences of participants. The study focused on 13 and 14 year olds to capture the considerable physical, social and emotional changes young teenagers go through, when body size and fatness are likely to be particularly salient.

\section{Recruitment of Participants}

The sample was drawn from families living in socio-economically disadvantaged circumstances because of evidence that young people living in such families are more likely to be overweight or obese (Armstrong \&Reilly, 2003). We contacted schools and youth groups in areas within Eastern Scotland classified as socio-economically disadvantaged as these were expected to contain a high proportion of young people who would fit our criteria of disadvantage. These areas were identified using the Breadline Britain Index (Gordon \& Forrest, 1995), a measure based on multiple measures of deprivation.

After receiving ethical approval from each relevant education authority, members of the research team visited three schools. Double consent was sought: parents were asked to 'opt out' if they did not wish their child to take part in the study and each young person was 
asked to give their own written consent before the study commenced. Ethical issues were discussed with each youth group before the study began and written consent was obtained from each participant. The youth groups and schools were disparate in terms of being attended by teenagers from semi-rural locations, and from small and medium sized towns.

\section{Data Collection}

A short screening questionnaire was administered to 8 classes of Secondary 2 pupils (the majority of whom were aged 13) and 4 classes of Secondary 3 pupils (the majority of whom were aged 14). The screening questionnaire was used to collect socio-demographic information (household composition; car use; occupation/s of parent/s; home postcode), physical activities undertaken regularly; whether the participant perceived their body to be too fat/too thin/about right and details of favourite, and regularly consumed foods. Each teenager who consented to the procedure also had their height and weight measured so that their Body Mass Index (BMI) could be calculated $\left(\mathrm{kg} / \mathrm{m}^{2}\right)$. Our sample was classified as being overweight or obese using the International Obesity Task Force thresholds for children, based on age, gender and UK reference data (Reilly, Dorosty \& Emmett, 1999). These are comparable to the adult thresholds of BMI, whereby a BMI $>25=$ overweight and a BMI > $30=$ obese (Cole, Bellizzi, Flegal \& Dietz, 2000). As our objective was to explore the embodied experiences of 'normal' weight, overweight and obese teenagers, young people who were underweight were excluded from the interview sample. Height and weight measurements were taken outside the classroom or youth club, usually in a medical room, empty classroom or other available private space, and each participant was weighed and measured without their shoes or outdoor coats. To ensure privacy, each participant was weighed without his or her peers present. The research team made great efforts to ensure that any anxiety that participants expressed about being weighed was addressed. However, 
a small minority of girls chose not to take part in the study because they said they were anxious about being weighed in school.

We selected 36 young people based on their agreement to be contacted about an interview, their gender (18 girls and 18 boys), their BMI (18 'normal' weight and 18 overweight or obese) and their socio-demographic details (we chose young people living in the most deprived postcode sectors within the area and account was also taken of household composition, parental occupation/s and car use). Each young person was interviewed at home, by the first author, for between 45 and 90 minutes. Although interviews were arranged when a parent or guardian was at home, they were not present during the interview. Parents were themselves interviewed at a later point in the study; these data will be reported elsewhere. A topic guide was used to prompt discussion about young people's everyday lives, their perceptions about health, food and eating, weight, body image and appearance. This included questions about participants’ own bodies and those of their family and friends. The interviewer avoided using value-laden terms related to body size and shape (e.g. fat and big) so that each participant could spontaneously introduce into the interview the terms with which they were familiar and comfortable. The questionnaire data were used to provide prompts within the interview. Interviews, which took place between February 2003 and January 2004, were tape-recorded with each respondent's consent.

\section{Data Analysis}

All interviews were transcribed in full and analysis began whilst the data were still being collected. This meant each theme that emerged could be explored in further detail in later interviews. All members of the research team read the transcripts repeatedly. Some members of the team read some of the transcripts without being aware whether each 
participant was 'normal' weight, overweight or obese. This ensured that themes were initially discussed and interpreted without interference from any preconceived ideas about individuals who are 'normal' weight, overweight or obese. Data were logged, coded and retrieved with the aid of the qualitative data-indexing package, QSR NUD*IST. Regular team meetings were then held to refine the analytical codes; to explore young peoples' underlying reasoning; to discuss data on young people who were dissimilar from their peers in some way; and to identify new research questions (Boyatzis, 1998; Richardson, 1996). All names used in this paper are pseudonyms and the data have been decontextualised where appropriate to ensure individuals cannot be identified.

\section{Findings}

Although teenagers with a BMI over the threshold for their age are defined as being overweight or obese, there has been little research which has examined how individuals who describe themselves as fat conceptualise their body size or shape. Analysis of the language used by teenagers illustrated how complex and, often, individualised, the conceptualisation of fatness and body size was. The participants seemed keen to try to convey as 'accurately' as possible to the interviewer what size they, or their friends and family were perceived to be, differentiating, for example, between big and fat when appropriate. These findings are discussed in this paper, along with some of the other themes which emerged from the data, namely, the perceived influences on body size/shape, the consequences of being fat, experiences of losing weight and interactions with friends and family related to fatness and dieting. 


\section{Conceptualisations of fatness and body size}

Regardless of BMI, most participants in the study used the words fat and big interchangeably when talking about their own and others' body size or shape. Some participants also frequently conceptualised fatter bodies in terms of being chubby or heavy. The terms podgy, stocky and tubby were also used, but less frequently than the other terms. The young teenagers who described themselves as fat were predominantly, but not exclusively, classified as being overweight or obese by their BMI. When talking about people being teased about their body size or shape, participants reported use of the word fat rather than any of the other words outlined here, giving fat a derogatory meaning as well as being a descriptor of body size or shape. For clarity, in this paper we only make reference to 'bigness' when participants differentiated between this and fatness, to make a specific point.

Very few teenagers in our study attempted to define exactly what they meant when referring to someone with a fat body. Those who did, referred to someone having floppy skin; having too much skin over their ribcage; having fat 'hanging down' or having flabby arms. Two boys were more specific, reporting that, for boys their age, 15 stone (210lbs) and 12 stone (168lbs) were excessive bodyweights (for an average height 14 year old boy, these body weights would define them as obese).

The term overweight was used, albeit infrequently, by many of the teenagers in the study, when referring to other people or when talking in abstract terms (rather than when talking about themselves). It was noticeable, though, that many of these references to overweight (and on fewer occasions, obesity) were made when talking about health or 'unhealthiness', rather than when talking about a person's body size or shape. In the following extract, 
Douglas, for example, talks about fatness when referring to his mother, but overweight people when talking about health (he did not describe his mother as being unhealthy during the interview):

Douglas: Well my Mum seems to think that she’s fat, and she lost a lot of weight, I didn’t really think she was fat.

Interviewer: What does being healthy mean?

Douglas: I don’t know really, but I picture overweight people as being unhealthy (Aged 14; 'Normal’ weight)

Most of the young teenagers in the study who were BMI-defined as 'normal' weight had little to say when asked how they felt about their own weight or body shape. The exceptions were Douglas, the only 'normal' weight boy to perceive himself as a 'bit too fat' and three girls, who disliked their bodies (or parts of their body) or wished to lose weight. Lorna, in particular, said she was very anxious about her weight gain and made constant negative references to her fat body:

Lorna: I wear big sizes and that to hide it, I dinnae want anybody to see my fat. Interviewer: How long has it really been bothering you for?

Lorna: Just...really, when I like started third year, that's all I thought about, my weight and my size. (Aged 14; 'normal’ weight)

The young teenagers who were BMI-defined as being overweight or obese often talked in contradictory and complex terms about their weight and body size. Three-quarters of these 
teenagers either had positive things to say about their weight, body size or parts of their body, or reported being comfortable with their body's size or shape. Nicole, for example, who was BMI-defined as obese, liked looking at her self in the mirror, particularly as she perceived herself as being thinner than a year ago:

Nicole: In primary school I was as fat as anything, in first year [at secondary school] I was not bad, but now I feel...for the last couple of years I was as podgy as anything, fat arms, and see now? When I look in the mirror at myself, ken [Scottish term meaning 'you know'], I used to hate looking in the mirror when I was fat, I used to hate looking in it, but now I look in it every day, my wee favour. Interviewer: Yeah? It makes you feel good?

Nicole: Aye (Aged 13; Obese)

A minority of participants who reported being comfortable with their body also said there were parts they disliked. Stomachs, thighs, legs and arms were described as being fat or not likable. About half of these teenagers also said they would like to lose weight or had previously tried to lose weight. The only participants who reported utter disapproval for their bodies were Nick and Rebecca, who had the highest BMIs in the sample, and Lorna, who was defined as being 'normal' weight, not overweight or obese. The majority of participants expressed more complex feelings about their bodies, which suggests there is not a straightforward relationship between BMI, lay definitions of overweight/obesity and 'normal' weight, body acceptance and desires to lose weight amongst young teenagers.

\section{Perceived influences on body shape and size}


Puberty was rarely reported explicitly as a cause of weight gain or a change in body size or shape, even though many participants described how their bodies had changed since they had left primary school, started secondary school and become a teenager - events that often precede or coincide with pubertal development. Half of the teenagers who were BMIdefined as being overweight/obese reported feeling frustrated that their appetite had increased or that their thighs, hips or stomachs had got fatter. These bodily changes were usually portrayed as being undesirable and something that girls, in particular, claimed to feel anxious about. Only one girl, Lucy, asked, when talking about her weight gain, “that’s usual, isn’t it?” Most of the boys reporting weight gain since leaving primary school, like Liam, quoted below, thought they would get taller and eventually grow out of their fatter bodies:

Interviewer: Has your shape or build changed as you've got older?

Liam: Yeah. I’ve been told I've been putting on weight because I'm gonna grow and my feet have grown about 5 and a half sizes since primary 7. (Aged 13; Overweight)

About half of our participants thought there was some similarity between their own build and that of specific, older, members of their family. Reports of being 'the double' of mothers, fathers, grandparents, aunts and uncles were common. Participants often described in some detail how their overall body shape or specific parts of their body resembled the bodies of older family members, as the following quote illustrates:

Interviewer: So did any of you talk about your different weights and heights after you'd all been [weighed for this study]? 
Lorraine: Mhm. And in my friends...cause I was...Robyn [her friend], she’s quite tall and she’s got big hips, big bum and that, but she’s no got a big belly or anything eh? That just runs in her family. Ma family, cause ma cousin Sarah, she’s quite thin but she's got a bum and hips sort of thing. Just runs in the family and that runs in Robyn's family as well. (Aged 13; Obese)

A minority of the teenagers also perceived that they would gain weight when they were older and resemble family members who had a bigger build than them. Some of the teenagers who raised the issue of heredity seemed to be reassured by shared, familial body shapes, claiming that individual efforts to change were unlikely to be successful because of these similarities.

Nevertheless, many of the teenagers in our sample stated, sometimes quite fervently, that it was their own personal responsibility to control their body size/shape and food consumption. When asked if parents had any responsibility for such matters, no participant perceived this to be the case. This responsibility weighed quite heavily on a minority of teenagers, with some, like Nick, describing how upset they felt that their bodies looked the way they did as a result of their own lack of willpower:

Interviewer: Some people have said that they think it's up to their parents to help them keep their weight down. And some people think it's, you know, it's down to them.

Nick: It's maybe like you..your parents, encouraging [you] and that sometimes Eh? But it's not down tae your parents. It's down to you. I mean if you're the one that wants to lose weight, then you can't say “Right, mum, 
can you lose weight for me?” Or em, that's up to you and you're the one who has to go oot for exercise and cut doon on your foods and that eh? That's... what I ken, it’s doon tae me eh...like some days, I mean, I just can’t even be bothered eh? But that's down tae me. I just can’t be bothered so I stay in [instead of taking exercise]. (Aged 13; Obese)

An increase or reduction in time spent on physical activity was perceived by over half of the overweight and obese teenagers to be a factor responsible for changes in their weight or body size. Whilst many of these teenagers felt they ran about more with their friends since leaving primary school, which meant weight gain could be minimised, the remainder of this group said they did not get many opportunities to exercise, partly because friends no longer wanted to undertake physically active games or sport.

\section{The consequences of being fat}

Much has been written about fat young people being the victim of bullying by their peer group. About half of the overweight and obese teenagers in the study reported being bullied or called names because of their weight, mainly at school, and most, like Evelyn, reported being unhappy or upset by this:

Evelyn: Well, Joanne [her friend] comes up ti me one day an' says I'm gettin’ too fat. An’ I stopped eatin’ for a couple ‘y weeks ‘cause she said that, ‘cause it hurt me. So I stopped eatin’ an’ my Mum... em, got on ‘y me, like she kept shoutin’ at me “You better eat your dinner” an’ aw that. Interviewer: Really, how did you feel?

Evelyn: Sad an’ sick, so I made mysel’ sick. (Aged 13; Obese) 
Two participants had changed secondary schools; one overweight girl said she had moved specifically because of bullying whilst the other had moved to a new area with his family and he said he was no longer bullied about his body at his new school. A minority of 'normal' weight participants stated bullying as a consequence of being a fat teenager and a potential reason for others to lose weight. One obese participant, Rebecca, acknowledged that the only reason she was not bullied about her weight was because she was part of a large and popular female friendship group and other teenagers were intimidated by her and her friends. Rebecca did, however, report being constantly criticised by her mother about her weight and her perceived overeating. Nick also reported being severely criticised about his eating habits and weight by his mother and maternal grandmother. Nick and Rebecca had the highest BMI of all the young people in the study. No other participants reported being 'bullied' by their family to lose weight. Despite the unpleasant nature of weightbased bullying, young people talked about being bullied for a variety of reasons and sometimes for no apparent reason at all. Several participants were aware that, even if fat teenagers changed their body size, they could still be bullied, as this quote from Lawrence illustrates:

People who diet are... [...], you know, they could've been pushed about for being overweight, but if they lose too much weight they could be pushed around for being too skinny and then they'll eat again and be fat again and then back the same as before. (Aged 13; Obese)

Two other consequences of being a fat teenager emerged from the data, with gender appearing to determine which participants raised these issues. Some teenagers, mainly girls, 
perceived that they were restricted in what clothes they were able to buy and wear because of their weight or body shape. Few of these participants reported feeling confident enough to wear the same clothes as thinner friends. This sometimes restricted shopping trips with friends, because of a fear of trying on clothes in front of other (thinner) peers. Other participants, mainly boys, reported that having a fatter body slowed them down when they were running about with their friends or taking part in sport, as the following quote illustrates:

Interviewer: What does it say on here [the questionnaire] about health? You put your health has been 'good' over the last 12 months. So what made you put 'good' and not 'excellent' [or 'poor']?

Craig: Because I get puffed out a wee bit more than my friends, some of them can run faster than me

Interviewer: Yeah? Why do you think that is?

Craig: Just because they're taller and thinner (Aged 13; Overweight)

\section{Experiences of losing weight}

Attempts at weight loss were reported by half the young teenagers defined as overweight or obese and by three of the 'normal' weight participants. Success at losing weight was always described in positive ways. Happiness (at managing to lose weight and seeing the 'result' in terms of a thinner body), pride (at 'successful' weight loss), excitement (at the thought of a thinner body) and feeling motivated (to continue to try to lose weight) were reported by both girls and boys who perceived they had become thinner by their own efforts. Adrian, for example, enjoyed the process of losing weight, as well as the benefits of 'successful' weight loss: 
Interviewer: Do you find being more active easier than cutting down on treats and fatty things or the other way around or is it both equally?

Adrian: Both actually. So I like being active, it’s more fun an' losin' weight just kinda... I just... I really just enjoy it apparently, 'cause I ken that I'm haein' fun at the same time, but it's makin' a physical difference and a mental difference, ken.

Interviewer: Yeah, how... explain that to me, what do you mean a mental difference?

Adrian: Well just like bein’ “Oh yeah, I’m losin’ weight” kinda 'hing, then you go “Oh that feels better” kinda 'hing, then you're... like “Oh I’m enjoyin' this, I can continue with it” (Aged 13; Obese)

Feelings of being in control and having willpower and self confidence were described as necessary for losing weight by some of the teenagers who had tried to do this. These teenagers acknowledged that such feelings about losing weight were difficult to invoke and sustain. This was often complex; for example, negative perceptions about being 'successful' at weight loss were reported by several boys. These participants were worried about becoming thinner in case they regained the weight lost, which, they reported, would result in feeling that their efforts had been wasted. Feeling a total 'failure' at losing weight, or expressing a need to constantly 'watch' what was eaten was reported by the two teenagers with the highest BMIs and by the participants who were 'normal' weight but who wanted to reduce their weight. These teenagers reported a sense of frustration at not being able to easily achieve weight loss, with failure linked to feeling upset, depressed, self- 
conscious and anxious. These findings suggest that young teenagers who want to lose weight experienced an emotional high when succeeding at weight loss and a deterioration in well-being when weight loss was not achieved.

Half the teenagers who wanted to lose weight spoke about increasing their physical activity as a more effective way of achieving this rather than changing what they ate. Although participants sometimes took up an organised activity like boxing, rugby or judo to lose weight, these teenagers were just as likely to report increasing the time they spent walking or 'running about' with friends. Gender appears to be important here. Most boys (like Roy, quoted below) reported weight loss when participating in organised physical activity:

Interviewer: so has it changed how you feel about your weight and your appearance, since you've been doing boxing and rugby and...? Roy: Mmhmm, aye, I feel a lot better wi’ mysel', 'cause I’m tryin' ‘y at least... ken I’m no’... ken I’m no’ just sittin’ doon aw day, I’m tryin’ ‘y lose a bit 'y weight (Aged 13; Overweight)

Girls, however, seemed more reluctant to undertake any form of exercise in order to control their weight, despite often expressing an interest in doing so. Sarah, for example, said that, although she was now walking more, she did not want to go swimming by herself.

Sarah: I’ve been doing like, making sure that I walk more, em and... Interviewer: yeah, and do you think that's, that's enough to make a difference [to your weight]?

Sarah: I don’t know, I might start, like I’m going to start like swimming 
more and that, just I need all of my pals to come with me, I don't like going [by] myself. (Aged 14; 'Normal' weight)

Although, when asked, about half of all teenagers in the study said that being fat was unhealthy, improved health was mentioned spontaneously by only a minority as a benefit of losing weight. A small number of participants also said that losing 'too much’ weight would have an adverse effect on health, mainly in terms of developing anorexia, but also because of weakened bones or premature death. It was notable that only a minority of participants voiced any tangible benefits of weight loss, even when questioned after expressing a desire to lose weight.

\section{Friends, family and fatness}

Most of our participants said they knew somebody who was trying to lose weight or who felt they were fat, but only a minority of teenagers seemed to believe that these actions or perceptions were justified. Most participants (regardless of their own BMI) reported that family and friends did not need to lose weight (or too much weight), or should not feel pressured to do so. It was, of course, not possible for the authors to confirm the accuracy of these perceptions, in terms of BMI, but mothers, fathers, sisters and friends were reported by both boys and girls as unhappy with their weight or trying to diet. When referring to parents, teenagers often expressed surprise that their mother or father saw themselves as being fat or needing to lose weight. Alison, for example, thought her father was muscular rather than fat:

Interviewer: Do you think anybody in your family’s ever tried to lose weight? 
Alison: My Dad. He thinks he’s fat but I always tell him it’s muscle, but he still thinks...so he goes jogging all the time.

Interviewer: How long has he been trying to lose weight?

Alison: For a wee while now, but nothing's coming off 'cause it's just muscle (Aged 13; 'Normal' weight)

Young people were usually quite outspoken when talking about friends' feelings about their own fatness. Some participants reported that friends who said they wanted to have thinner bodies did so as a way of drawing attention to themselves; of validating their already 'normal' weight bodies; or because they were worried about what others thought of them. Teenagers, like Amanda, were frequently quite dismissive of such 'fat-talk':

Amanda: My friend Paige, she says like "I'm fat", and it's like "Paige you're not fat” and she’s like “I am”, and people say she’s fat, but she’s not, she’s really thin.

Interviewer: Why do you think they think that then? Amanda: I don't know. I think they are just worrying about what other people are going to say about them (Aged 13; Overweight)

Some young teenagers also said they were not supportive when friends thought they were fat because of fears about eating disorders and extreme weight loss and weight loss behaviours. It was quite common for teenagers, particularly girls, to comment on the speed with which some friends lost weight, which was not viewed as beneficial:

Interviewer: Have you got friends your age that try and lose weight? 
Jodie: Aye, well Fiona she used to be, I... like there was nothing o' her figure but she's got this new boyfriend and I think she’s trying to lose weight. And she’s really skinny. She used to be like, she went fae [from] like a size twelve, noo she's a size eight. And that was only like a couple of months. [...] Interviewer: Right, do you talk to her about it?

Jodie: I did say tae her the last time I was there that I thought she had lost too much in a wee period of time but she said there was nothing tae worry aboot. (Aged 14; Obese)

Most of the young teenagers who reported trying to lose weight gave accounts that suggested family or friends sometimes expressed negativity or suspicion about their own weight loss efforts, if these were perceived as being excessive or obsessive. 'Sensible' weight loss attempts were usually supported by family members, although friends were occasionally perceived as being negative about any attempts to lose weight.

\section{Discussion}

This study explored the everyday, embodied perceptions of young obese, overweight and 'normal' weight teenagers in relation to their weight, body image and bodily concerns. By using qualitative methods, our study accessed young teenagers' perceptions of their own and others' body weight and size. We have shown that overweight and obese young teenagers have complex and, often, contradictory, feelings about their own and others' bodies. Young people with bodies defined by their BMI as overweight and obese referred to themselves as fat and big (but not overweight or obese) and also referred to others in this way. Wadden \& Didie (2003) found that obese men and women disliked the term fatness, preferring terms like heavy and unhealthy bodyweight. However, those individuals (who 
were considerably older than those in our sample) were asked about the preferred descriptors of 'excess' weight they would like their GP or other health professionals to use. Other research (Paquette \& Raine, 2004) has suggested that people react differently to weight issues when they are raised in a health care, as opposed to other settings.

Whilst some participants used the words overweight and obesity when talking about 'unhealthiness', few teenagers mentioned (over)weight in relation to consequences for health and only a minority of teenagers raised any benefits at all of losing weight. The current (medicalised) health promotion and public health messages about (over)weight and obesity are, therefore, unlikely to resonate with young teenagers. There is a danger, however, that if health educators and healthcare professionals start to use non-medicalised terms (e.g. 'fat', 'heavy') when trying to communicate with young people, this will be perceived as inappropriate. This needs to be explored further.

Surveys have identified that teenagers often think they are overweight, even when their BMI is within the 'normal' range for their age group, with girls being more likely than boys to perceive that their bodies are fatter than they should be (Sweeting \& West, 2002). The minority of 'normal' weight girls in our study who disliked their bodies or wanted to lose weight often reported anxiety and distress about their perceived fatter bodies and said they constantly watched what they ate and took exercise to lose weight. Such findings concur with other studies (Stice, Cameron, Hayward, Taylor \& Killen, 1999; Ryan, Gibney \& Flynn, 1998; Nowak, 1998). There were similarities between these 'normal' weight girls in our study and the two participants who were extremely obese, Nick and Rebecca. Unlike the majority of overweight and obese teenagers interviewed, they said that they disliked their bodies and undertook extreme measures in order to lose weight. However, in contrast, 
acceptance of body size/shape and positive comments about parts of the body were commonly expressed by the overweight and obese participants (although some of them said they wished to lose weight, or reported they had done so in the past). This runs counter to some of the literature on body image and body satisfaction (e.g. Williams \& Currie, 2000).

People from working class backgrounds, like the participants in this study, have been reported as being more satisfied with their overweight bodies than their middle class peers (Wardle and Griffith, 2001). It is impossible to draw firm conclusions about the importance of social class without comparison with young people from higher socio-economic groups. However, taken-for-granted bodily practices are grounded in the social and economic contexts in which they are produced and reproduced (Williams 1995) and it is likely that this, in part, is responsible for our participants’ perceptions about their weight and body size. Whereas middle class teenagers may value thinness and therefore hold negative attitudes to overweight/obesity (Wardle et al. 1995), young teenagers from working class backgrounds may value bodies that are simply free from illness and capable of performing everyday activities (Bourdieau 1984; d’Houtard and Field 1984). Certainly some of the overweight and obese boys in the study said they valued being able to run about with their friends and did not like it when their fatter bodies slowed them down.

There was a notable lack of evidence in our findings of a shared culture of dieting amongst friendship groups. Whilst others have shown common attitudes to dieting and shared weight loss attempts amongst teenage peer groups (Eisenberg et al., 2005), we found that most teenagers in our study expressed concern or frustration when others perceived that they were fat or wanted to lose weight. Some participants said that friends and family were unsupportive of their own attempts to lose weight, particularly if this involved crash 
dieting. There was no evidence that, when a participant reported trying to lose weight, his or her friends (who were sometimes also in our interview sample) expressed a similar intention. Shared dieting practices could, however, be a phenomenon that is associated only with teenagers who are not overweight or obese (Eisenberg et al., 2005). Rather than an apparent fear of fatness (Sweeting \& West, 2002), some of our participants expressed a fear or dislike of extreme dieting, thinness, eating disorders, and anxiety or 'attention seeking' behaviour related to a perceived fat body. Whilst such findings have not been reported widely before (though Wertheim, Paxton, Schutz \& Muir (1997) also reported that teenagers dislike 'fat talk'), no other qualitative study in the UK has included young teenagers, from working class families, who are overweight and obese. We argued, above, that the social and economic contexts within which young teenagers live out their lives could be responsible for the body satisfaction we found amongst those defined as overweight or obese. Similarly, such class distinctions could be responsible for the lack of shared dieting discourses expressed by our participants.

Recent attention on young, obese bodies has focused on encouraging young people to normalise their body size through changes to eating habits or increased physical activity (Royal College of Physicians, 2004). Whilst in our study, successful weight loss was reported to be allied with positive benefits for well-being, none of those who were defined as overweight or obese said that losing weight was related to a desire to change their body's shape or size. Weighing less or seeing numbers reduce on a scale could act as motivating factors in themselves and, as the quote from Adrian earlier in the paper indicated, emotions involved in the process of losing weight and seeing the 'result' were clearly important. Feelings of failure from a perceived inability to diet were commonly expressed by participants who were 'normal' weight or very obese. Other studies have suggested that 
dieting is related to body dissatisfaction (Hoerr, Kallen \& Kwantes, 1995), stigmatisation (O’Dea, 2004) and weight gain (Stice et al., 1999), but our findings suggest that these effects are only evident in a minority of teenagers who attempt to lose weight in this way. Gaining a sense of physicality through exercise or sport can be empowering, particularly for young women (Garrett, 2004), but disengaging with sport during secondary school is, paradoxically, quite common for girls (Williams, Bedward \& Woodhouse, 2000), particularly when peers are not supportive (Neumark-Sztainer, Story, Hannan, Tharp \& Rex, 2003). Although, in this study, boys often expressed dismay that their weight slowed them down, they could still use their physicality, regardless of their size, to feel in control of their bodies.

Findings from quantitative studies have suggested that overweight adolescents are socially isolated (Strauss \& Pollack, 2003) and frequently teased (Eisenberg et al., 2003). We found that the young teenagers who reported being bullied because of their weight or size, whilst often upset about this, were no more likely to report body dissatisfaction than the other participants who did not report being bullied. Only the two severely obese participants reported being constantly criticised by their families about their eating habits and weight, although Eisenberg et al. (2003) report that weight-based teasing by family members is only marginally less common than teasing by peers.

\section{Conclusion}

BMI definitions of 'normal' weight, overweight and obesity are too simplistic to take account of the complexity of feelings that young teenagers have about their own and others' bodies. This study focused on one geographical area of Scotland, and on young teenagers living in socio-economically disadvantaged circumstances and therefore our teenagers' 
accounts may not extrapolate to a wider population. Nevertheless, our findings draw attention to the ways in which the current medicalised view that 'thin is good' whilst 'fat is bad' overlooks the perceptions of the population who are thought to be in greatest need of protection. Using qualitative methods, we have been able to provide a detailed exploration of the bodily perceptions of young people labelled by their BMI as obese, overweight or 'normal' weight. Including these 'least listened to' groups has helped to uncover important findings which dispel some of the myths about obesity in young people. We found that not all overweight/obese teenagers are bullied (just as not all bullying is related to body size); that bodies defined by their BMI as being overweight/obese are not always perceived as fat or unacceptable and that not all teenagers (particularly girls) are striving for thinness. We hope that this study, and any further work which arises from it, will inform and challenge current public health debates about teenage obesity.

\section{References}

Armstrong, J., \& Reilly, J.J. (2003). The prevalence of obesity and undernutrition in Scottish children: Growth monitoring within the child health surveillance programme. Scottish Medical Journal, 48: 32-37.

Bordo, S. (1993). Unbearable Weight: Feminism, Western Culture and the Body. Berkeley, Ca. University of California Press.

Bourdieu, P. (1984). Distinction: A Social Critique of the Judgement of Taste. London: Routledge and Kegan Paul.

Boyatzis R.E. (1998). Transforming Qualitative Information: Thematic Analysis and Code Development. Thousand Oaks, CA, Sage.

Britten, N., Jones, R., Murphy, E., \& Stacy, R. (1995). Qualitative research methods in general practice. Family Practice, 12(1):104-14. 
Cole, T., Bellizzi, M., Flegal, K., \& Dietz, W. (2000). Establishing a standard definition for child overweight and obesity worldwide: international survey. British Medical Journal, 320: 1-6.

D’Houtard, A. \& Field, M. (1984). Images of health: variations in perceptions by social class in a French population. Sociology of Health and Illness, 6: 30-60.

Eisenberg, M., Neumark-Sztainer, D., \& Story, M. (2003). Associations of weight-based teasing and emotional well-being among adolescents. Archives of Pediatrics and Adolescent Medicine, 157: 733-738.

Evans, B. (2004). Be fit not fat: Broadening the childhood obesity debate beyond dualisms. Children’s Geographies, 2(2): 289-291.

Featherstone, M. (1991). The body in consumer culture. In: M. Featherstone, M. Hepworth, \& B. Turner (Eds.), The Body: Social Process and Cultural Theory. London, Sage.

Frosh, S., Phoenix, A., \& Patman, R. (2002). Young Masculinities: Understanding Boys in Contemporary Society. Basingstoke, Palgrave/Macmillan.

Frost, L. (2003). Doing bodies differently? Gender, youth, appearance and damage. Journal of Youth Studies, 6(1): 55-70.

Frost, L. (2001). Young Women and the Body: A Feminist Sociology. Basingstoke, Palgrave.

Garrett, R. (2004). Negotiating a physical identity: Girls, bodies and physical education. Sport, Education and Society, 9(2): 223-237.

Gordon, D. \& Forrest, R. (1995). People and Places volume II: Social and economic distinctions in England - A 1991 Census Atlas. Bristol, SAUS Publications and the Statistical Monitoring Unit. 
Hoerr, S., Kallen, D., \& Kwantes, M. (1995). Peer acceptance of obese youth: A way to improve weight control efforts? Ecology of Food and Nutrition, 33: 203-213.

Janssen, I., Craig, W., Boyce, W. \& Pickett, W. (2004). Associations between overweight and obesity with bullying behaviors in school-aged children. Pediatrics, 113(5): 11871194.

Jeffery, A., Voss, L., Metcalf, B., Alba, S. \& Wilkin, T. (2004). Parents' awareness of overweight in themselves and their children: cross sectional study within a cohort (EarlyBird 21). British Medical Journal, 330: 23-24.

Lupton, D. (1994). Medicine as Culture: Illness, Disease and the Body in Western Societies. London, Sage.

Miles, S., Cliff, D., \& Burr, V. (1998). "Fitting in and sticking out”: consumption, consumer meanings and the construction of young people's identities'. Journal of Youth Studies, 1(1): 81-96.

National Audit Office (2001). Tackling Obesity in England. London, The Stationery Office.

Neumark-Sztainer, D., Story, M., Hannan, P., Tharp, T. \& Rex, J. (2003). Factors associated with changes in physical activity. Archives of Pediatrics and Adolescent Medicine, 157(8): 803-810.

Nowak, M. (1998). The weight-conscious adolescent: body image, food intake, and weightrelated behavior. Journal of Adolescent Health, 23(6): 289-298.

O’Dea, J. (2004). Prevention of child obesity: ‘First, do no harm'. Health Education Research, Advance Access 24 August 2004, Doi:10.1093/her/cyg116.

Paquette, M. \& Raine, K. (2004). Sociocultural context of women’s body image. Social Science and Medicine, 59: 1047-1058. 
Reilly, J.J., Dorosty, A. \& Emmett, P. (1999). Prevalence of overweight and obesity in British children: cohort study. British Medical Journal, 319: 1039.

Richardson, J.T.E. (1996). Handbook of Qualitative Research Methods for Psychology and the Social Sciences. Leicester, BPS Books.

Royal College of Physicians (2004). Storing Up Problems: The Medical Case for a Slimmer Nation. London, Royal College of Physicians.

Ryan, Y., Gibney, M., \& Flynn, M. (1998). The pursuit of thinness: A study of Dublin schoolgirls aged 15years. International Journal of Obesity, 22(5): 485-487.

Stice, E., Cameron, R., Hayward, C., Taylor, C.B., \& Killen, J. (1999) Naturalistic weightreduction efforts prospectively predict growth in relative weight and onset of obesity among female adolescents. Journal of Consulting \& Clinical Psychology, 67(6): 967-974. Strauss, R. (2000). Childhood obesity and self-esteem. Pediatrics, 105(1): 15-20. Strauss, R. \& Pollack, H. (2003). Social marginalization of overweight children. Archives of Pediatrics and Adolescent Medicine, 157: 746-752.

Sweeting, H., \& West, P. (2002). Gender differences in weight related concerns in early to late adolescence. Journal of Epidemiology and Community Health, 56: 700-701.

Wadden, T. \& Didie, E. (2003). What's in a name? Patients' preferred terms for describing obesity. Obesity Research, 11(9): 1140-1146.

Wardle, J. \& Griffith, J. (2001). Socioeconomic status and weight control practices in British adults. Journal of Epidemiology and Community Health, 55: 185-190.

Wardle, J., Volz, C., \& Golding, C. (1995). Social variation in attitudes to obesity in children. International Journal of Obesity, 19(8): 562-569.

Wertheim, E., Paxton, S., Schutz., \& Muir, S. (1997). Why do adolescent girls watch their weight: An interview study examining sociocultural pressures to be thin. Journal of Psychosomatic Research, 42(4): 345-355. 
West, P. \& Sweeting, H. (2004). Evidence on equalisation in youth from the West of Scotland. Social Science \& Medicine, 59(1): 13-28.

Williams, A., Bedward, J. \& Woodhouse, J. (2000). An inclusive curriculum? The experience of adolescent girls. European Journal of Physical Education, 5(1): 4-18. Williams, J., \& Currie, C. (2000) Self-esteem and physical development in early adolescence: Pubertal timing and body image. Journal of Early Adolescence, 20(2): 129149.

Williams, L., \& Germov, J. (1999). The thin ideal: Women, food and dieting. In: J.

Germov, \& L. Williams, (Eds). A Sociology of Food and Nutrition. Melbourne, Australia, Oxford University Press.

Williams, S. (1995). Theorising class, health and lifestyles: can Bourdieau help us? Sociology of Health and Illness, 17(5): 577-604. 